\title{
Associative olfactory learning in the desert locust, Schistocerca gregaria
}

\author{
Patrício Simões, Swidbert R. Ott and Jeremy E. Niven* \\ Department of Zoology, University of Cambridge, Cambridge CB2 3EJ, UK \\ *Author for correspondence (nivenje@gmail.com)
}

Accepted 20 April 2011

\begin{abstract}
SUMMARY
Locusts can learn associations between olfactory stimuli and food rewards, and use the acquired memories to choose between foods according to their nutrient requirements. They are a model system for both the study of olfactory coding and insect nutritional regulation. Previous studies have used operant paradigms for conditioning freely moving locusts, restricting the study of the neural mechanisms underlying the acquisition of olfactory memories, which requires restrained preparations for electrophysiological recordings. Here we present two complementary paradigms for the classical conditioning of olfactory memories in restrained desert locusts (Schistocerca gregaria). These paradigms allow precise experimental control over the parameters influencing learning. The first paradigm is based on classical (Pavlovian) appetitive conditioning. We show that opening of the maxillary palps can be used as a measure of memory acquisition. Maxillary palp opening in response to odour presentation is significantly higher in locusts trained with paired presentation of an odour and a food reward than in locusts trained either with unpaired presentation of food and odour or the odour alone. The memory formed by this conditioning paradigm lasts for at least $24 \mathrm{~h}$. In the second paradigm, we show that classical conditioning of an odour memory in restrained locusts influences their decisions in a subsequent operant task. When locusts that have been trained to associate an odour with a food reward are placed in a Y-maze, they choose the arm containing that odour significantly more often than naïve locusts. A single conditioning trial is sufficient to induce a significant bias for that odour for up to $4 \mathrm{~h}$. Multiple- and block-trial training induce a significant bias that lasts at least $24 \mathrm{~h}$. Thus, locusts are capable of forming appetitive olfactory memories in classical conditioning paradigms and can use these memories to modify their decisions.
\end{abstract}

Supplementary material available online at http://jeb.biologists.org/cgi/content/full/214/15/2495/DC1

Key words: appetitive conditioning, classical conditioning, decision-making, learning, memory, olfaction.

\section{INTRODUCTION}

Insects can learn associations between events in their environment and use these associations to modify their behaviour including feeding, predator avoidance, aggression, and social and sexual interactions (Dukas, 2008; Chittka and Niven, 2009). Indeed, many different forms of learning have been demonstrated in insects, including state-dependent valuation (Pompilio et al., 2006), interval timing (Boisvert and Sherry, 2006) and delayed matching to sample (Giurfa et al., 2001). These associations reduce environmental unpredictability and can confer an increase in fitness by, for instance, enhancing foraging efficiency (Dukas and Bernays, 2000), though they can also incur costs (Mery and Kawecky, 2005).

Insects rely heavily on olfaction for various behaviours and are able to associate an odour with different environmental features, such as food or host location, nutritional value or noxious stimuli (Papaj and Prokopy, 1989; De Boer and Dicke, 2006; Dukas, 2008). Olfactory conditioning in insects typically involves the pairing of an odour [conditioned stimulus (CS)] with an appetitive or aversive stimulus [unconditioned stimulus (US)] that is known to elicit a strong and unconditioned response (Papaj and Prokopy, 1989). Such training may be undertaken in a classical (Pavlovian) conditioning paradigm with the insect restrained and unable to locomote. Alternatively, it may contain both classical and operant conditioning components if the paradigm requires that the insect must move to a particular location where the CS/US association is made (Carew and Sahley, 1986; Papaj and Prokopy, 1989). Following training, olfactory memories are tested for retention by measuring the behaviour of the conditioned insects upon presentation of the CS alone. Retention can be measured either through the presence or absence of a particular behaviour that is thought to represent the acquisition of a conditioned response (e.g. Bitterman et al., 1983) or by quantifying a continuous behavioural readout such as the time spent near an odour source (e.g. Balderrama, 1980; Matsumoto and Mizunami, 2000), distance from the source (e.g. Simpson and White, 1990) or number of individuals gathering near it (e.g. Tully and Quinn, 1985).

Locusts have been shown to learn in several contexts, being capable of both appetitive and aversive associative learning using either odours, tastes or colours as the CS (Szentesi and Bernays, 1984; Bernays and Lee, 1988; Lee and Bernays, 1990; Simpson and White, 1990; Bernays, 1993; Raubenheimer and Blackshaw, 1994; Raubenheimer and Tucker, 1997; Behmer et al., 1999; Behmer et al., 2005; Pompilio et al., 2006; Dukas and Simpson, 2009). To our knowledge, however, olfactory associative learning in locusts by Pavlovian conditioning has not been shown. Previous studies have used conditioning procedures that combined Pavlovian and operant aspects, making it difficult to control the precise strength of the learned associations. In most instances, associative conditioning was tested through continuous measures of preference, such as latencies, feeding times or entry distances that are strongly modulated by satiation and motivational state (but see Behmer et al., 2005). 
The economic significance of locusts as crop pests and their complex feeding ecology has made them a model for invertebrate nutritional regulation. Locusts are generalist herbivores, able to integrate the intake of variable mixtures of nutrients with their own physiological state (Simpson and Raubenheimer, 2000; Behmer, 2009). Behavioural and electrophysiological investigations using synthetic diets, which locusts readily consume, demonstrate that locusts use both learning and nutrient-specific modulation of taste receptor responsiveness to regulate their intake of protein, carbohydrate, salt and water (Simpson and Raubenheimer, 2000). A fully parameterized conditioning paradigm is, however, necessary to investigate the specific role of learning in nutrient regulation. Locusts are also a model system in which to study olfactory processing and have been used to elucidate fundamental principles of odour coding in the insect brain (for a review, see Laurent, 2002). However, the lack of a behavioural correlate that can be used to monitor the acquisition or retention of olfactory memories in restrained locusts has been an obstacle to analyzing odour coding in relation to olfactory memory acquisition, storage and recall at the level of single neurones and neural circuits.

In this paper, we present two novel and complementary olfactory appetitive conditioning paradigms that allow the assessment of learning in desert locusts (Schistocerca gregaria). A key advantage of both paradigms is that locusts are restrained during training, thus allowing precise control of the learning parameters. We described the opening of the locusts' maxillary palps [palp opening response (POR)] as a new behavioural measure of acquisition of an olfactory Pavlovian association. Desert locusts subjected to associative training showed significantly more PORs and preferred the CS over a novel odour for at least $24 \mathrm{~h}$. By measuring the odour preference of locusts in a Y-maze, we also showed that locusts can use olfactory appetitive memories to make relevant decisions in a different context. A single training trial was sufficient to induce a significant bias towards the CS for up to $4 \mathrm{~h}$, whereas multiple and block-trial training induced an odour bias for at least $24 \mathrm{~h}$. Thus, restrained locusts can acquire and retain olfactory associative memories in a classical conditioning paradigm and use these memories to make relevant decisions in an operant task.

\section{MATERIALS AND METHODS Locusts}

Gregarious desert locusts (Schistocerca gregaria Forskål 1775) were taken from a crowded colony maintained at the Department of Zoology, University of Cambridge, UK. Locusts in the colony were raised on a diet of seedling wheat and wheat germ. Adult locusts of either sex were taken from the colony a minimum of 5 days after their last moult. Batches of approximately 40 adult locusts were transferred from the colony to a heated holding tank $(24 \times 30 \times 20 \mathrm{~cm}$, $35^{\circ} \mathrm{C}$ ) where they remained except during training and testing.

\section{Acquisition experiments}

The POR, a behaviour that is first described in this study (see Results), was used as a measure of appetitive memory acquisition during associative conditioning in locusts. For the acquisition experiments, locusts were secured in Plasticine ${ }^{\circledR}$, allowing them to move only their antennae and mouthparts, and then placed under a $100 \mathrm{~W}$ heat lamp for $5 \mathrm{~min}$ to rest. The appetitive US was standard locust artificial diet (Simpson et al., 1988), with an equal protein to carbohydrate ratio mixed with the same weight of water. The US was delivered to a locust's mouth on a small metal spatula. Pure lemon extract (Holland \& Barrett, Nuneaton, Warwickshire, UK) was used as the CS and pure vanilla extract (DrOetker, Thorpe Park,
Leeds, UK) was used in the retention tests as the novel odour. The setup used for training and behavioural testing is shown schematically in Fig. 1A. Five microlitres of undiluted odour extract was applied to $1 \mathrm{~cm}^{2}$ of filter paper placed inside the plastic cap of a $40 \mathrm{~mm}$ needle (BD Microlance 3, Fraga, Huesca, Spain). The two needles containing the two different odours were connected to a switch-controlled air pump and inserted into PVC tubing that delivered a constant flow of blank air. The end of the tubing was directed towards the locusts' antennae and placed approximately $5 \mathrm{~cm}$ away. Odour stimuli were presented by switching on the air pump connected to the respective needle to inject the odour into the constant flow of blank air. A video camera (Microsoft web cam) was placed below the exit of the tubing in front of the locust to record the behaviour. A red LED behind the locust automatically turned on at the same time as the pump to indicate the timing of odour delivery in the video footage (Fig. 1A; supplementary material Movie 1).

A training session lasted $1 \mathrm{~h}$ and consisted of six training trials. Each trial lasted $1 \mathrm{~min}$ and began by placing the locust in front of the blank constant air flow for $25 \mathrm{~s}$ to become accustomed to the setup. The CS was then presented to the locust for $10 \mathrm{~s}$. Depending on the experimental group, the CS was either paired with the US or unpaired (see Results). The presence or absence of a POR was recorded during the first $5 \mathrm{~s}$ of CS presentation, prior to presentation of the US (if any). After presentation of the odour, the locust was left undisturbed for the remaining $25 \mathrm{~s}$ before being removed from the experimental apparatus. The locusts remained secured in Plasticine ${ }^{\circledR}$ and were tested for the presence of the POR at $10 \mathrm{~min}$, $1 \mathrm{~h}$ and $24 \mathrm{~h}$ after the last training trial. Such tests, used to measure the retention and specificity of the acquired memory, consisted of two trials separated by $10 \mathrm{~min}$. In each trial, the CS or the novel odour were presented for $10 \mathrm{~s}$ without any US. Half of the locusts were presented with the CS first, and then with the novel odour, vanilla. The odour presentation was reversed for the other half.

\section{Olfactory conditioned preference experiments}

In these experiments, locusts were first submitted to olfactory conditioning while restrained, and then tested in a $\mathrm{Y}$-maze arena. After being starved for $24 \mathrm{~h}$, locusts were secured in Plasticine ${ }^{\circledR}$ and allowed to rest for $5 \mathrm{~min}$ before training. The US was the locust artificial diet mixed with the same weight of water. The CS consisted of $25 \mu \mathrm{l}$ of pure lemon extract placed on $1 \mathrm{~cm}^{2}$ of filter paper, which was then placed inside a plastic tube connected to an air pump. The end of the tubing was directed towards the locusts' antennae and placed $5 \mathrm{~cm}$ away. Associative conditioning consisted of one or more training trials. A locust was placed in front of the tubing $20 \mathrm{~s}$ prior to the trial. Each trial consisted of a $5 \mathrm{~s} \mathrm{CS}$ presentation followed by $20 \mathrm{~s}$ of simultaneous CS/US presentation (Fig. 1B). After the trial, the locust remained in the same position for $20 \mathrm{~s}$ before being removed from the setup. In experiments with more than one trial, the inter-trial interval (ITI) was $5 \mathrm{~min}$. Animals failing to feed in any training trial were discarded. After training, the locusts were gently removed from the Plasticine ${ }^{\circledR}$ and returned to the holding tank until testing.

The test arena was a two-arm $\mathrm{Y}$-maze containing a raised wooden Y-shaped rod (Fig. 1B). The maze was $22 \mathrm{~cm}$ in height and $10 \mathrm{~cm}$ wide, the long arm was $24 \mathrm{~cm}$ in length and the two decision arms were $15 \mathrm{~cm}$ in length. The two arms of the $Y$-maze were separated by $90 \mathrm{deg}$ and the top was covered with transparent plastic, providing a clear view of the animals throughout the test. Access to the $Y$ maze was by a lid in the top of the maze. A $100 \mathrm{~W}$ heat lamp was placed above the junction of the arms of the maze. The locusts were 

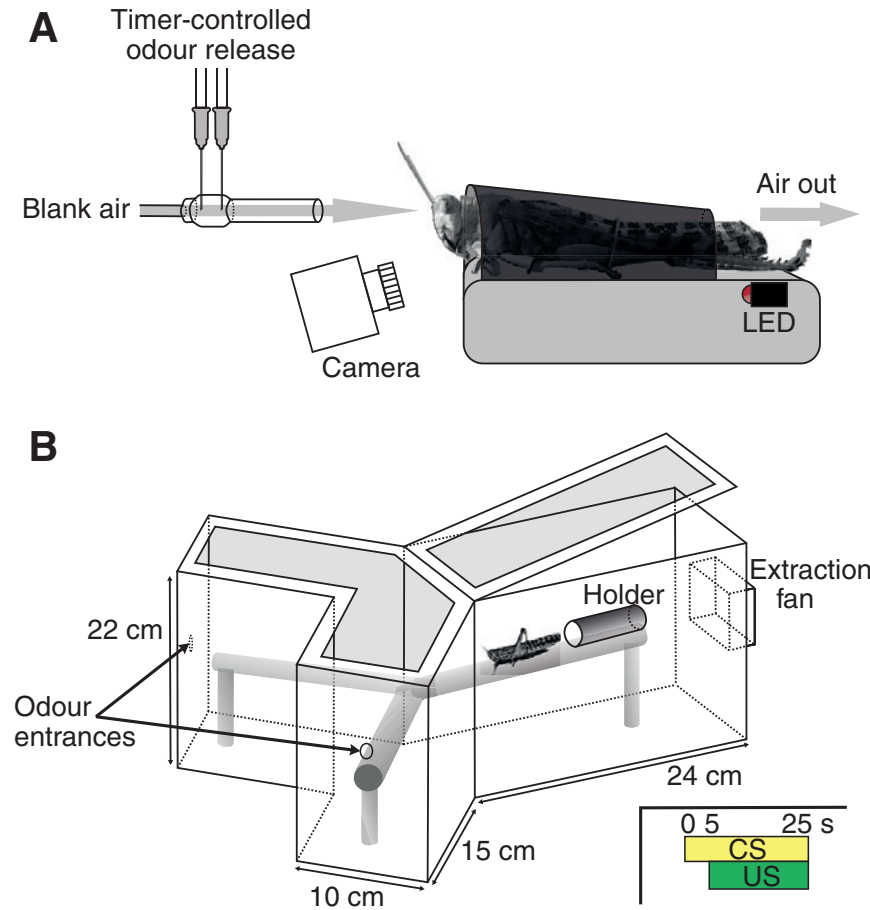

Fig. 1. Diagram of the apparatus for training and testing. (A) Desert locusts secured in Plasticine ${ }^{\circledR}$ received a constant flow of blank air directed to the antennae. Odours were delivered using a timer-controlled air pump, which also switched on the LED during the odour presentation. The LED is hidden from the locust's view. A video camera recorded both the locust's behaviour and the LED. (B) The Y-maze. Plastic containers with different pure odour extracts were connected to each odour entrance and to an air pump. Locusts were placed inside the holding tube, which was then attached to the Y-shaped wooden rod. After exiting the tube, a locust had $5 \mathrm{~min}$ to make a decision towards one of the arms. They were only allowed to walk along the wooden rod. Each locust was only tested once. Inset: training schedule used in the olfactory conditioned preference experiments.

allowed to walk only along the $\mathrm{Y}$-shaped wooden rod that occupied the central space of the arena. The wooden rod had a circular crosssection $2.5 \mathrm{~cm}$ in diameter and was raised $11 \mathrm{~cm}$ above the floor of the $\mathrm{Y}$-maze. Its main arm was $21 \mathrm{~cm}$ long and each decision arm was $13 \mathrm{~cm}$ long. Before each test, the experimental locust was placed inside a cylindrical Plexiglas ${ }^{\circledR}$ holding tube $(10 \mathrm{~cm}$ long, $2.5 \mathrm{~cm}$ in diameter) that was attached to the rod using Velcro ${ }^{\circledR}$. The end of the tube facing the junction was open, allowing the locusts to exit, and the other end was covered with mesh to allow air flow through the holder. In the centre of the end walls of the Y-maze decision arms, a $1 \mathrm{~cm}$ diameter hole allowed the passage of odours into the maze. A small plastic vial containing approximately $1 \mathrm{ml}$ of pure odour extract was connected to an air pump and to one of these holes. A $12 \mathrm{~V}$ extraction fan was mounted at the opposite end of the $\mathrm{Y}$-maze. The air pump and the extraction fan provided a stable air flow inside the $\mathrm{Y}$-maze from the decision arms to the end of the long arm (Fig. 1B).

Locusts were subjected to a single odour preference test in the $\mathrm{Y}$-maze $10 \mathrm{~min}, 2,4$ or $24 \mathrm{~h}$ after training. One of the decision arms contained the CS whereas the other contained the novel odour. Half of the animals were tested with the CS in the right arm and the other half with the CS in the left arm. A locust was first placed inside the holder and left undisturbed for a few seconds. The air flow inside the $\mathrm{Y}$-maze was turned on and the holding tube was placed on the main arm of the rod at the position closest to the extraction fan
(Fig. 1B). Each locust was allowed $5 \mathrm{~min}$ to exit the holder and to make a choice. A choice was registered when a locust walked to the end of a decision arm and touched the wall with either the front legs or antennae. Locusts that failed to make a decision within $5 \mathrm{~min}$ or that fell or jumped off the rod were discarded $(<10 \%$ of the animals tested). After each test, the locust was removed from the Y-maze and the wooden rod was cleaned with $70 \%$ alcohol to disperse possible pheromonal cues and left to dry.

\section{Statistical analysis}

In the acquisition experiments, the presence or absence of a POR was registered for each individual. For the $\mathrm{Y}$-maze experiments, the individual decision towards a particular odour was registered. Consequently, all the statistical tests used reflected the binary nature of the response variables. In all experiments, the locusts' sex was balanced and $G$-tests for independence were used to test whether sex affected their behaviour. Yate's correction for continuity was used to avoid overestimation of significance when response counts are low (Sokal and Rohlf, 1998). No significant sex differences were observed in any of the experiments. Therefore, the data from both sexes were pooled within each experimental group.

In POR acquisition experiments, the effect of successive training and retention tests was analyzed using the Cochran test $(Q)$. The proportion of PORs between experimental groups was compared using $G$-tests for homogeneity $\left(G_{\mathrm{H}}\right)$. If the results of these tests were heterogeneous, analyses were complemented using multiple comparison $\chi^{2}$ Yates tests. Individual learning performance was compared between pairs of experimental groups using the nonparametric Mann-Whitney $U$-test. In multiple comparisons tests, significance was corrected with the Dunn-Sidak correction, where $\alpha^{\prime}=1-(1-\alpha)^{1 / k}$, where $k$ is the number of comparisons performed on the same data sample (Zar, 1999). The order of CS and novel odour presentation was balanced in all three retention tests. We used the $\chi^{2}$ Yates to test whether the order in which odours were presented affected the locusts' response during retention. Data from both odour presentation orders were pooled within each treatment group because there was no significant effect of the order of odour presentation.

In the Y-maze, the position of the odour relative to the decision arm was balanced within each experimental group. We used $G$-tests for goodness-of-fit to determine whether there was divergence from an expected $50 \%$ decision for each arm side. The data relative to arm side were pooled within each group because no significant side bias was observed in any of the experiments. The naive olfactory preference of locusts was used as an extrinsic null hypothesis against which the preference of conditioned locusts was compared using $G$-tests for goodness of fit. The effect of training schedule on odour preference was tested using $G$-tests for homogeneity. The sources of heterogeneity within significant data sets were then analyzed using unplanned tests of homogeneity, where the critical $G$-value equals $\chi_{\alpha[(a-1)(b-1)]}^{2}$, where $\alpha$ is the significance threshold $(\alpha=0.05), a$ is the number of treatment groups and $b$ is the number of possible outcomes of an independent variable ( $b=2$ possible odour choices) (Sokal and Rohlf, 1998).

\section{RESULTS POR}

We sought to identify an anticipatory behaviour in restrained locusts that could represent a conditioned response. Locusts were restrained and presented repeatedly with an unfamiliar odour (CS) that was paired with a food reward (US) in the form of balanced artificial diet. We observed that during these training sessions, 

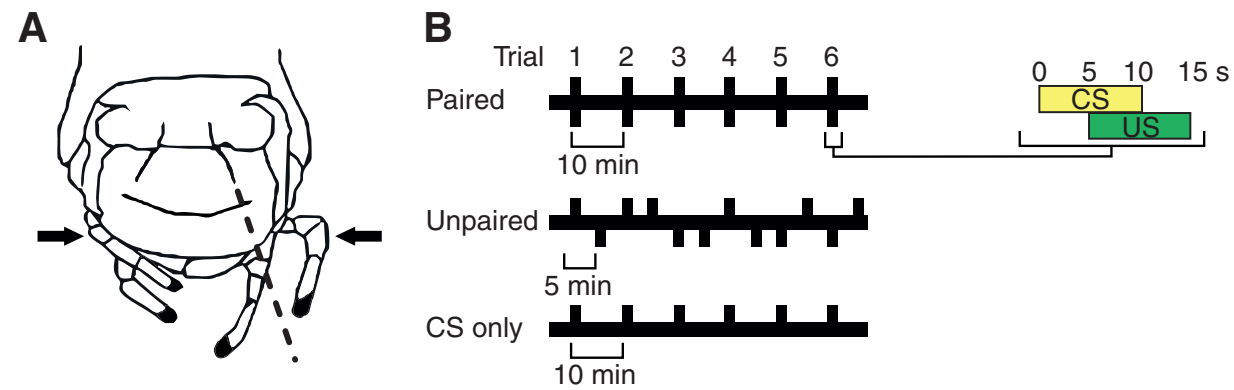

Fig. 2. Palp opening response (POR) conditioning. (A) Diagram of the head of Schistocerca gregaria showing the labrum and maxillary (black arrows) and labial palps. At rest, the palps are held loosely curved beneath the head (left). A POR was considered to be any levation of the maxillary palps outwards and away from the head beyond an imaginary line (dashed line) formed by the lateral groove of the labrum (right). (B) Diagrams of the paired, unpaired and conditioned stimulus (CS) only conditionings. Fifty-six locusts were trained in each group during $1 \mathrm{~h}$. Paired training consisted of six CS/unconditioned stimulus (US) trials with an inter-trial interval (ITI) of $10 \mathrm{~min}$. The unpaired group experienced the same number of CS and US during the training as the paired group, but the stimuli presentation was pseudorandom and with a $5 \mathrm{~min}$ ITI. A pseudorandom unpaired sequence was determined a priori for each locust. The CS only group was presented with six CS trials without any US presentation.

locusts began to display a characteristic and stereotyped opening of the maxillary palps at the onset of the CS (POR). At rest, the maxillary palps are usually held loosely beneath the head (Fig. 2A). Movements of the palps are related to feeding and play an important role in food selection (Chapman and Sword, 1993). Movements comprise isolated palp flickings, rapid vibration of both palps and outward extensions of the maxillary palps away from the midline of the head (Blaney and Chapman, 1970; Chapman and Sword, 1993). We define a POR as any levation of one or both maxillary palps outwards and away from the head, regardless of the movement type (flicking, palpation or outward opening) (Fig.2A; supplementary material Movie 1). The labial palps frequently opened simultaneously with the maxillary palps. These movements were more difficult to observe and less reliable, however, so we did not include them in our analysis.

\section{Acquisition of the POR}

Our observations suggested that the POR was a suitable behavioural measure of associative learning. Therefore, we characterized the induction of the POR in our olfactory conditioning paradigm. First, we investigated whether the frequency of PORs during CS presentations increased with paired training. The POR was quantified by a binary classification: the response was positive if the tip of the palp crossed an imaginary line formed by the lateral groove of the labrum (dashed line, Fig. 2A). We trained 56 locusts with six trials separated by an ITI of $10 \mathrm{~min}$. During each trial, the CS was presented for $10 \mathrm{~s}$. Five seconds after the onset of the CS, food (US) was presented to the locust's mouthparts for $10 \mathrm{~s}$ on a metal spatula (paired, Fig. 2B; supplementary material Movie 1). Palp opening was registered if it occurred within the time window between the onset of the CS and the US. Locusts that opened their palps on the first trial were discarded $(<15 \%)$ to control for previous exposure or innate sensitivity to the CS. We also excluded locusts that did not accept the US during any of the trials $(<10 \%)$. The first trial was excluded from our analysis because it was designed to have a null response. There was a significant increase in the frequency of palp openings over the subsequent five consecutive trials (Cochran's test, $Q=14.50$, d.f.=4, $P<0.01$; Fig. 3). During the second trial, $25 \%$ of the locusts showed a POR to presentation of the paired CS. The percentage of locusts showing PORs increased to $43 \%$ in the third trial and $52 \%$ in the last training trial.
We observed the frequency of PORs in two control groups - an unpaired group and a CS only group - to test whether the increased probability of eliciting a POR was conditional upon an association between the odour and the food reward. Locusts in the unpaired group were presented with the same number of CS and US as the paired group but without the temporal paring between the food and odour. Thus, the training consisted of 12 trials with a 5 min ITI and, in a given trial, a locust received only either the CS or the US for $10 \mathrm{~s}$. The stimuli were presented in a pseudorandom sequence determined for each individual, with the first trial always a CS and with none of the stimuli given more than two consecutive times (unpaired, Fig. 2B). As in the paired group, we considered only those locusts that accepted the US in all trials ( $>90 \%)$. Only trials in which the CS was presented were considered in the analysis. The unpaired group showed a constant rate of PORs of $11-13 \%$ in trials 2 through 6 that did not increase significantly during training $(Q=0.17$, d.f. $=4$, $P=0.99$; Fig. 3). Locusts in the CS only group were presented with six CS trials without any US presentation and with an ITI of $10 \mathrm{~min}$ (CS only, Fig. 2B). The percentage of PORs in the CS only group did not increase significantly during training, remaining at $7-11 \%$ in trials 2 to $6(Q=1.03$, d.f. $=4, P=0.91$; Fig. 3$)$.

The training effect occurred rapidly. Differences in POR frequency between the different experimental groups were already significant in trial 2 , with a higher percentage of responses in the paired group than in either the unpaired or CS only groups ( $G$-test for homogeneity, $G_{\mathrm{H}}=7.34$, d.f. $=2, P=0.03$; Fig. 3). This difference became increasingly pronounced over the subsequent training trials (trial 3: $G_{\mathrm{H}}=21.82$; trial 4: $G_{\mathrm{H}}=24.26$; trial 5: $G_{\mathrm{H}}=31.06$; trial 6: $G_{\mathrm{H}}=35.84$; all d.f. $=2, P<0.001$; Fig. 3). The response rates in the two control groups were not significantly different in any of the training trials (trial 2: $G_{\mathrm{H}}=9.18$; trial 3: $G_{\mathrm{H}}<0.001$; trial 4: $G_{\mathrm{H}}=0.38$; trials 5 and 6: $G_{\mathrm{H}}=9.18$; all d.f. $=1, P>0.3$; Fig. 3 ). Thus, the increased proportion of PORs in the paired group is specifically due to the co-presentation of the CS/US and not to separated presentation of the stimuli or to odour sensitisation. Hence, the POR can serve as a behavioural measure of acquisition of an appetitive associative conditioned response.

How does paired presentation of CS/US affect the responses of individual locusts over the consecutive trials? Individuals in the paired group typically showed two PORs over the five trials (median), significantly more than individuals in the unpaired group (median=0; Mann-Whitney $U$-test, $U=719, P<0.001$; Dunn-Sidak 


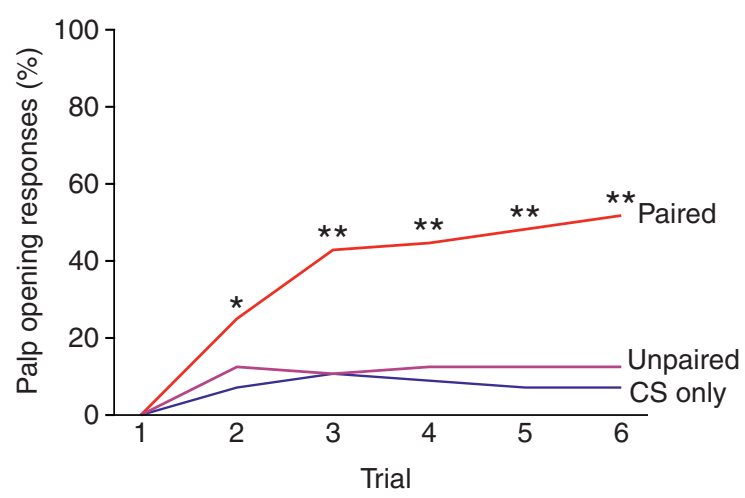

Fig. 3. Percentage of desert locusts showing PORs to odour stimulation during acquisition. Significant differences are denoted with asterisks $\left({ }^{\star} P<0.05 ;{ }^{*} P<0.001\right)$. The POR significantly increased on the course of the six conditioning trials when CS was paired with US $(Q=59.69$, d.f. $=5$, $P<0.001)$. The POR remained constant across training when the US was temporally unpaired $(Q=9.22$, d.f. $=5, P=0.10)$ or absent $(Q=7.35$, d.f. $=5$, $P=0.20$ ). For comparative purposes only, the responses during the CS trials were considered in the unpaired group. Responses become significantly higher in the paired group compared with the unpaired and CS only groups from the second training trial onwards.

correction $\alpha^{\prime}=0.017$ ) and in the CS only group (median $=0, U=595$, $\left.P<0.001, \alpha^{\prime}=0.017\right)$. The unpaired and CS only groups showed no significant difference $\left(U=1413, P=0.25, \alpha^{\prime}=0.017\right)$. In the paired group, $79 \%$ of locusts responded at least once to the onset of the CS, compared with only $32 \%$ in the unpaired group and $23 \%$ in the CS only group $\left(G_{\mathrm{H}}=41.75\right.$, d.f. $\left.=2, P<0.001\right)$. Moreover, $30 \%$ of the individuals in the paired group responded in four or five out of the five trials, compared with only $2 \%$ in both the unpaired and CS only groups $\left(G_{\mathrm{H}}=29.77\right.$, d.f. $\left.=2, P<0.001\right)$. The increased frequency of PORs in the paired group, therefore, reflected an increase in both the number of locusts responding and the number of responses per locust.

\section{Retention tests}

We assessed whether the associative memory formed during training was retained $10 \mathrm{~min}, 1 \mathrm{~h}$ and $24 \mathrm{~h}$ after the last training trial and if the responses were specific to the trained odour (CS). The trained odour or a novel odour was presented without any US. However, $10 \mathrm{~min}$ after each retention test, locusts were assessed for satiation and physical condition by presenting food to their mouths. Only those locusts that accepted the food after all three retention tests were considered $(>95 \%)$. The training schedule significantly influenced the proportion of PORs to the trained odour for all retention times ( $10 \mathrm{~min}: G_{\mathrm{H}}=30.90 ; 1 \mathrm{~h}: G_{\mathrm{H}}=27.23 ; 24 \mathrm{~h}: G_{\mathrm{H}}=55.73$; all d.f. $=2, P<0.001 ;$ Fig. 4 ). The paired group showed a significantly higher proportion of PORs to the trained odour than the unpaired group (10 min: $\chi^{2}$ Yates $=10.30 ; 1 \mathrm{~h}: \chi_{\text {Yates }}^{2}=11.51 ; 24 \mathrm{~h}: \chi^{2}$ Yates $=34.50$; $P<0.001, \alpha^{\prime}=0.017$ each test) and the CS only group (10 min: $\chi^{2}$ Yates $=24.08 ; 1 \mathrm{~h}: \chi^{2}$ Yates $=20.79 ; 24 \mathrm{~h}: \chi^{2}$ Yates $=38.94$; all $P<0.001$, $\alpha^{\prime}=0.017$ ). In contrast, the two control groups did not differ significantly in their response to the trained odour for any of the retention times $\left(10 \mathrm{~min}: \chi^{2}\right.$ Yates $=3.13, P=0.08 ; 1 \mathrm{~h}: \chi^{2}$ Yates $=1.23$, $P>0.25 ; 24 \mathrm{~h}: \chi^{2}$ Yates $\left.=0.05, P>0.75 ; \alpha^{\prime}=0.017\right)$. These results showed that PORs to the onset of the trained odour are more frequent when the locusts had been trained previously in a paired associative schedule, suggesting that the paired CS/US presentations induced an appetitive associative memory that is retained and retrieved for at least $24 \mathrm{~h}$.

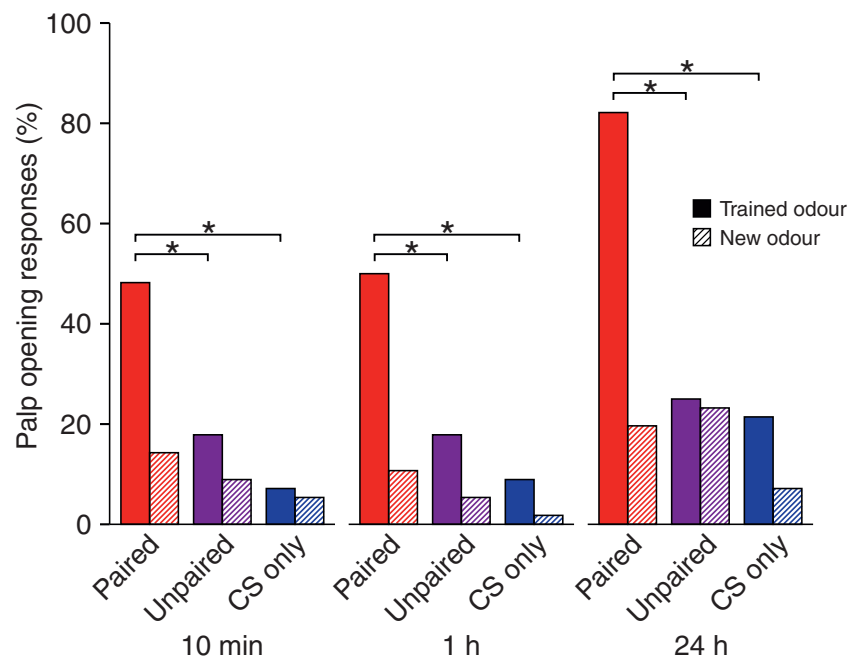

Fig. 4. Percentage of desert locusts showing PORs to the trained odour and to a novel odour $10 \mathrm{~min}, 1 \mathrm{~h}$ and $24 \mathrm{~h}$ after training. Each retention test consisted of two trials where each odour was presented without the US and with an ITI of $10 \mathrm{~min}$. Locusts responded significantly more to the trained odour when they were previously trained with the CS paired with the US than when trained with unpaired or CS only schedules. The PORS to the trained odour were similar between the control groups. In all tests, the PORs were significantly higher than those to the new odour when locusts were trained with the CS paired with the US (10 min: $\chi^{2}$ Yates $=13.46$, $P<0.001 ; 1 \mathrm{~h}: \chi^{2}$ Yates $=18.62, P<0.001 ; 24 \mathrm{~h}: \chi^{2}$ Yates $\left.=41.30, P<0.001\right)$ and were similar to the PORs in the unpaired (10 min: $\chi^{2}$ Yates $=1.23, P=0.27 ; 1 \mathrm{~h}$ : $\chi^{2}$ Yates $=3.13, P=0.08 ; 24 \mathrm{~h}: \chi^{2}$ Yates $\left.<0.001 ; P<1.00\right)$ and $C S$ only groups (10 min: $\chi^{2}$ Yates $<0.001, P<1.00 ; 1 \mathrm{~h}: \chi^{2}$ Yates $=1.58, P=0.21 ; 24 \mathrm{~h}: \chi^{2}$ Yates $<3.57$, $P=0.06) .{ }^{*} P<0.001$.

We then assessed whether the locusts discriminated between the trained odour and a novel stimulus to determine whether the responses during the retention tests were specific to the CS. Locusts conditioned with a paired schedule responded significantly more to the trained odour (Fig. 5A,B; supplementary material Movie 1) than to the novel odour (Fig. 5C,D; supplementary material Movie 1) across all three retention tests $\left(10 \mathrm{~min}: \chi^{2}\right.$ Yates $=13.46 ; 1 \mathrm{~h}$ : $\chi^{2}$ Yates $=18.62 ; 24 \mathrm{~h}: \chi^{2}$ Yates $=41.30$; all $P<0.001 ;$ Fig. 4$)$. The majority of locusts in this group responded solely to the trained odour (41-63\%), whilst only $4-7 \%$ of locusts responded solely to the novel odour. However, the proportions of PORs to the trained versus the novel odour were never significantly different in the unpaired group (10 min: $\chi_{\text {Yates }}^{2}=1.23, P=0.27 ; 1 \mathrm{~h}: \chi_{\text {Yates }}^{2}=3.13, P=0.08 ; 24 \mathrm{~h}$ : $\chi^{2}$ Yates $<0.001, P<1.00$; Fig. 4$)$ or the CS only group (10 min: $\chi^{2}$ Yates $<0.001, P<1.00 ; 1 \mathrm{~h}: \chi^{2}$ Yates $=1.58, P=0.21 ; 24 \mathrm{~h}: \chi^{2}$ Yates $<3.57$, $P=0.06$; Fig. 4$)$. In the unpaired group, the majority $(64-82 \%)$ of the individuals did not respond to any odour and only $13 \%$ (in each retention test) responded solely to the trained odour (Fig.4). Likewise, in the CS only group, the majority (78-91\%) of individuals were not responsive to any odour and a response to the trained odour occurred in $5 \%$ of individuals in the $10 \mathrm{~min}$ test, $9 \%$ in the $1 \mathrm{~h}$ test, and $14 \%$ in the $24 \mathrm{~h}$ test (Fig. 4). These results show that locusts submitted to a paired conditioning schedule respond differentially to the trained and novel odours and that this differential response is maintained for at least $24 \mathrm{~h}$. Locusts in the CS only and unpaired groups responded slightly, although not significantly, more often to the trained odour than to the novel odour, suggesting that some sensitization to the trained odour may have occurred.

Repeated odour presentation without reward may lead to a reduced responsiveness to the CS and the novel odour due to extinction 

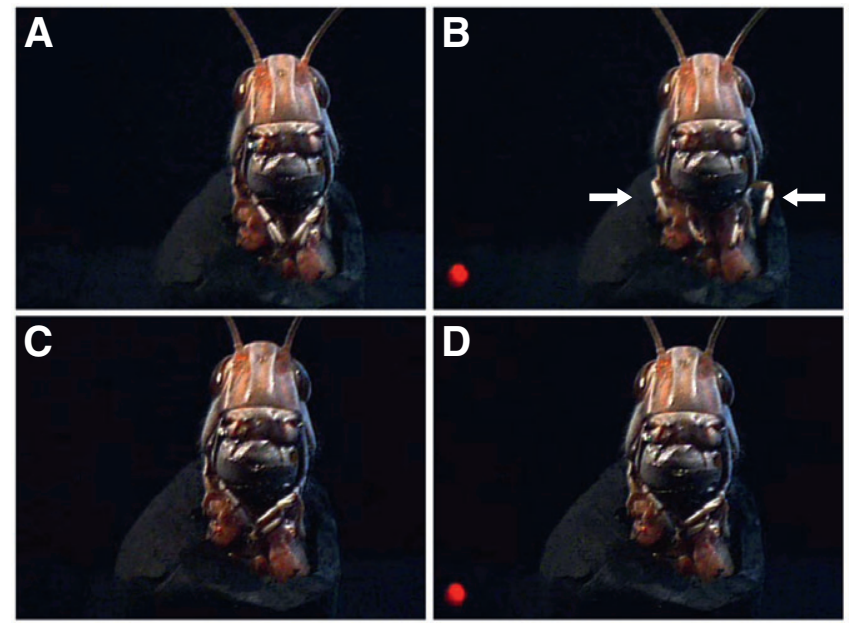

Fig. 5. PORs during retention tests. (A) Locust maxillary palps held loosely underside before the presentation of the trained odour. (B) PORs (white arrows) during the onset of the trained odour (red LED). (C) Locust maxillary palps before the onset of the novel odour. (D) Locust maxillary palps during the onset of the novel odour (red LED) showing no palp opening behaviour.

or habituation, respectively. Therefore, we analyzed the effect of repeated presentations of the trained and novel odours on the proportion of PORs across the three retention times. Responsiveness to the trained odour varied significantly across the retention trials in the paired and CS only groups (paired: $Q=20.18$, d.f. $=2, P<0.001$; CS only: $Q=9.57$, d.f. $=2, P<0.01$; Fig. 4). In both groups, the response to the CS was highest on the third unrewarded trial, $24 \mathrm{~h}$ after training, indicating that extinction had not occurred. The proportion of PORs to the CS remained constant for the unpaired group $(Q=1.78$, d.f. $=2, P=0.40$; Fig. 4$)$. The proportion of responses to the novel odour, however, remained constant in the paired and CS only groups, but differed significantly in the unpaired group, which showed a higher responsiveness to this odour in the last retention test (paired: $Q=1.81$, d.f. $=2$, $P=0.40$; CS only: $Q=2.00$, d.f. $=2, P=0.39$; unpaired: $Q=10.50$, d.f. $=2, P=0.005$; Fig. 4). These results indicate that the three consecutive unrewarded tests we used to assess olfactory memory of conditioned locusts caused neither extinction nor habituation.

\section{Associative conditioning of odour preference}

Associative learning may confer a selective advantage only if the memories are used to inform behavioural choices whose outcome is relevant to the animal, for example, during foraging. To test whether past appetitive associative conditioning can modify such choices, we presented locusts with a choice between vanilla and lemon odour in a $\mathrm{Y}$-maze. We first determined the odour preference of naïve locusts in this behavioural context $(N=44) ; 68 \%$ of naïve locusts preferred the arm with vanilla odour, the remaining $32 \%$ preferred the arm with lemon odour. This proportion was significantly different from the 50:50 distribution expected if there were no preference for either odour ( $G$-test, $G=5.95$, d.f.=1, $P<0.05)$. Although there are no reports of the relative attractiveness of these odours in $S$. gregaria, there are previous accounts of the innate repellence of lemon odour in the migratory locust Locusta migratoria (Simpson and White, 1990), and a strong preference for vanilla odour has been described in both in the cricket Gryllus

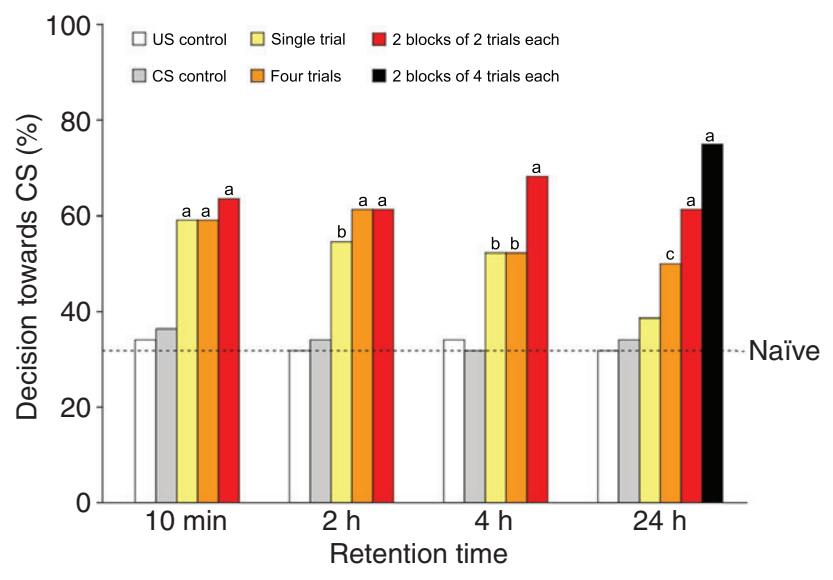

Fig. 6. Percentage of desert locusts that choose the arm with the lemon odour (CS) over the vanilla odour during the Y-maze test in four different retention intervals. In each group, 44 locusts were tested, with sex and odour position balanced. A single test was performed in each animal. The dashed horizontal line represents the odour preference of naïve desert locusts. The letters represent different $P$-values for the test against the naïve preference (a: $P<0.001$; b: $P<0.01$; c: $P<0.05$; groups without letters were not significant).

bimaculatus (Matsumoto and Mizunami, 2000) and in the cockroach Periplaneta americana (Balderrama, 1980).

Olfactory conditioning was designed to work against the locusts' naïve preference for vanilla over lemon odour. Thus, lemon was used as the CS and was paired with a food reward (US). Ten minutes, 2,4 or $24 \mathrm{~h}$ after training, a locust was placed in the $\mathrm{Y}$-maze, where it was allowed to choose between the arm containing lemon odour (CS) and the arm containing vanilla odour (naïve preference). If the locust associated lemon odour with the food reward and used this memory in the operant $\mathrm{Y}$-maze task, we would expect an increase in the proportion of locusts selecting the arm containing lemon odour whereas control locusts should show preferences similar to those of naïve animals.

A single paired CS/US presentation was sufficient to increase the number of locusts that preferred lemon when tested $10 \mathrm{~min}, 2 \mathrm{~h}$ and $4 \mathrm{~h}$ after training (10 min: $G=13.80, P<0.001 ; 2 \mathrm{~h}: G=9.65$, $P<0.01$; 4 h: $G=7.86, P<0.01$; Fig. 6). However, 24 h after a single training trial, the preference was no longer significantly different from the naïve preference $(G=0.91, P=0.33)$. Locusts exposed to four paired trials showed a significant shift in their preference towards lemon at all four retention times tested, including $24 \mathrm{~h}$ after training (10 min: $G=13.8, P<0.001 ; 2 \mathrm{~h}: G=16.16, P<0.001 ; 4 \mathrm{~h}$ : $G=7.86, P<0.01 ; 24$ h: $G=6.24, P<0.05$; Fig. 6$)$. Control locusts were conditioned either with four trials of CS only or four trials of US only. None of the controls had preferences that differed significantly from the naïve preference (CS only, $10 \mathrm{~min}: G=0.41 ; 2 \mathrm{~h}: G=0.1$; 4h: $G=0$; 24 h: $G=0.1$; all $P>0.5$; US only, $10 \mathrm{~min}: G=0.1 ; 2 \mathrm{~h}: G=0$; 4h: $G=0.1 ; 24$ h: $G=0$; all $P>0.75$; Fig. 6). We also assessed the effect of block training on the proportion of odour preference in the locusts because multiple training trials presented in blocks spaced out over time are thought to increase the consolidation of olfactory associative memories (Rankin and Dubnau, 2007). The inter-block interval used in training the locusts was $1 \mathrm{~h}$. Locusts trained with two blocks of two trials each showed a significant preference for lemon over all tested retention times ( $10 \mathrm{~min}: G=18.70 ; 2 \mathrm{~h}: G=16.16$; $4 \mathrm{~h}: G=24.39$; 24h: $G=16.16$; all $P<0.001$; Fig. 6). Locusts trained with two blocks of four trials each and tested $24 \mathrm{~h}$ later showed the highest percentage 
of choices (75\%) to the CS arm ( $G=34.52, P<0.001$; Fig. 6$)$. Together, these results show that appetitive associative conditioning influenced the locusts' olfactory preference in an operant task for at least $24 \mathrm{~h}$ and that a single training trial was sufficient to elicit a short-term change in odour preference.

The different conditioning schedules affected the strength of the preference for the $\mathrm{CS}$ arm at all retention times that we tested (10 min: $G_{\mathrm{H}}=14.07$, d.f. $=4 ; 2$ h: $G_{\mathrm{H}}=15.27$, d.f. $=4 ; 4$ h: $G_{\mathrm{H}}=16.17$, d.f. $=4 ; 24$ h: $G_{\mathrm{H}}=26.34$, d.f. $=5$; all $P<0.01$; Fig. 6 ). In the same-day retention tests, paired training schedules and controls formed two separated homogeneous groups (unplanned tests of homogeneity; paired training: $10 \mathrm{~min}: G_{\mathrm{H}}=0.26 ; 2 \mathrm{~h}: G_{\mathrm{H}}=0.56 ; 4 \mathrm{~h}: G_{\mathrm{H}}=3.09$; controls: $10 \mathrm{~min}: G_{\mathrm{H}}=0.05 ; 2 \mathrm{~h}: G_{\mathrm{H}}=0.05 ; 4 \mathrm{~h}: G_{\mathrm{H}}=0.05$; all $P>0.2$; critical $\chi^{2}=9.49$ each test). However, after $24 \mathrm{~h}$, block-trained schedules formed a homogenous group distinct from all other schedules (block trained: $G_{\mathrm{H}}=1.90, P=0.17$; other schedules: $G_{\mathrm{H}}=3.60, P=0.31$; critical $\chi^{2}=11.07$ each test). These results indicate that associations formed by block training resulted in a stronger preference for the CS after $24 \mathrm{~h}$, even when the number of trials was the same between the multiple- and block-training schedules.

\section{DISCUSSION}

We have used a novel appetitive learning paradigm to demonstrate that restrained desert locusts can learn to associate a specific odour with a food reward. We describe for the first time the maxillary POR and demonstrate that it can serve as a robust and sensitive behavioural metric to monitor the acquisition of an association in restrained locusts. Memories formed in this paradigm were maintained for at least $24 \mathrm{~h}$. In a second paradigm, locusts that had been restrained during training were subsequently released and shown to use olfactory memories to make appropriate decisions in a different setting, choosing the arm of a $\mathrm{Y}$-maze containing the conditioned odour. The duration over which these memories lasted depended on the number of training trials. A single training trial induced a memory that influenced the locusts' choices in the $\mathrm{Y}$-maze for at least $4 \mathrm{~h}$. Multiple training sessions led to memories that influenced the locusts' choices in the $Y$-maze for at least $24 \mathrm{~h}$.

Restraining the locusts during training ensures that those parameters with a crucial influence on learning - such as the number, duration and sequence of stimulus presentations and the inter-trial and inter-block intervals - are under experimental control and that learning is entirely by Pavlovian association. This contrasts with previous studies where Pavlovian and operant aspects were not separated (e.g. Simpson and White, 1990; Behmer et al., 2005; Dukas and Simpson, 2009).

We established that the POR of locusts provides a robust behavioural measure of an appetitively conditioned associative memory. The increased rate of PORs during training was due to the CS/US contingency and was not caused by contextual cues, as shown by the lack of an increased rate of PORs in control animals. The memories formed were specific to the trained odour, with locusts discriminating between odours and presenting the correct behavioural response to the odour presented. We observed that the control groups showed a slightly higher proportion of PORs in response to the CS odour than the novel odour. Although this trend was not statistically significant, it may indicate some sensitization during training, which could be reduced by reducing the time interval and concentration of the $\mathrm{CS}$ during training. The proportion of PORs did not decrease during the successive retention tests. Indeed, the observed trend is an increase $24 \mathrm{~h}$ after training, which may reflect memory consolidation or a change in the motivational state of the animals because they were restrained and starved throughout the tests.

How does the POR compare with other behavioural measures of associative memory in other insects? Honeybees typically show a high and asymptotically saturating rate of proboscis extension reflexes (PERs) during olfactory conditioning; after three or four training trials, more than $80 \%$ of bees responded to the CS presentation (Bitterman et al., 1983; Hammer and Menzel, 1995), and this memory lasted at least $72 \mathrm{~h}$ (Menzel et al., 1993). Studies in other insect species that have a proboscis achieved similarly high response rates by paired training. For example, four or five training trials lead to a PER rate of 70-75\% in the moths Heliothis virescens (Hartlieb, 1996) and Spodoptera littoralis (Fan et al., 1997), whereas the cibarial pump reflex of Manduca sexta was observed in 50-70\% of the moths (Daly and Smith, 2000). The PER rate in Drosophila melanogaster reached $60-80 \%$, but this is set against a rate prior to conditioning between 20 and 40\% (Chabaud et al., 2006). In contrast, only a maximum of $44 \%$ of bumble bees, Bombus terrestris, showed a PER after a 10-trial olfactory conditioning (Laloi et al., 1999).

Olfactory conditioning of an insect without a proboscis has only recently been accomplished in the ant Camponotus aethiops (Guerrieri and d'Ettorre, 2010). In these ants, a maxilla-labium extension response to a CS can be elicited after olfactory associative training. The response rate was $40-50 \%$ during training, which is similar to the rate of PORs that we observed during the olfactory conditioning of locusts. This suggests that olfactory conditioning of mouthpart movements in insects lacking a proboscis may not be as sensitive as that in insects with a proboscis. However, whether this is a genuine biological difference or simply due to methodological differences is unclear. A possible biological explanation might be found in the fact that, in honeybees, extension of the proboscis is an absolute mechanical prerequisite for the ingestion of food (Rehder, 1987), whereas opening the palps is not (Blaney and Chapman, 1970). The neural control of the PER might, therefore, be coupled to the same control system that also initiates the subsequent motor pattern that controls licking (Rehder, 1987). In contrast, the locusts' palps are essentially sensory structures (Blaney and Chapman, 1970). Because the palps are used to probe and manipulate food, ingestion in locusts is not mechanically dependent upon a fixed palp motor pattern and neural control of the palps might be flexibly coupled to different pre-motor systems.

Locusts are a model system for the study of insect olfactory processing, where the circuit architecture and dynamics are well known; however, little is known about how the repeated complex transformations in odour representations from the antennal lobe to the mushroom body, the presumed site of odour learning, relate to, support and change during associative learning (Laurent, 2002). The POR opens up new experimental possibilities to address these fundamental questions by providing a behavioural measure for associative learning in restrained locusts, which will permit the changes in odour coding to be monitored at the circuit and cellular levels during the acquisition, storage and recall of olfactory memories.

Conditioned reflexes that are evoked by the CS in classical conditioning paradigms tell little about the relevance of the learning capability in question for natural behaviour in freely moving animals. Thus, retention tests should be performed in an operant context, where insects can freely behave in response to the learned stimulus. Previous studies in fruit flies (Tully and Quinn, 1985), honeybees (Sandoz et al., 2000; Chaffiol et al., 2005) and crickets (Matsumoto and Mizunami, 2002a) have shown that insect olfactory 
memories are resistant to such context changes. In the cricket, classical olfactory conditioning evoked a subsequent change in olfactory preference in an open test arena that lasted from $2 \mathrm{~h}$ to 4 days (Matsumoto and Mizunami, 2002a; Matsumoto and Mizunami, 2002b). Our results showed that desert locusts are also able to transfer classically conditioned appetitive olfactory memories to operant contexts. A single training trial was sufficient to elicit a significant increase in the number of locusts choosing the arm of the $\mathrm{Y}$-maze containing the $\mathrm{CS}$ for at least $4 \mathrm{~h}$. Training with multiple trials or blocks of trials increased the duration over which the locusts chose the CS arm. After 24h, block-trained locusts showed a stronger odour preference than those trained with a single trial or multiple trials, even when the number of trials was the same. These results suggest that different memory mechanisms may be evoked by different training schedules. One of the hallmarks of memory is a gradual consolidation from an initially labile phase into progressively more stable and lasting memory phases (Rankin and Dubnau, 2007). This model of multiple memory phases in insect olfactory learning has been supported with studies on honey bees (Menzel, 1999), fruit flies (Margulies et al., 2005) and crickets (Matsumoto and Mizunami, 2002a). Although details vary between species, different memory phases can be defined by the training regimes that induce them (single trial or multiple trials, which could be massed or spaced), by the resistance to anaesthesia and by the susceptibility to inhibition of protein synthesis (Rankin and Dubnau, 2007). The trainingdependent memory retention in our paradigm suggests that it is sufficiently sensitive to allow further dissection of these different mechanisms of olfactory memory formation in locusts.

The ability of training to alter the odour preference of locusts through learning for at least 1 day supports their generalist feeding ecology. Desert locusts are polyphagous herbivores faced with complex and variable mixtures of nutrients and deterrent or toxic compounds from a large array of host plants. Accordingly, associative learning has been shown to contribute to the regulation of nutrient intake in locusts (Simpson and Raubenheimer, 2000). As our results show, a single training trial induced only a shortterm change in odour preference, whereas multiple or block-spaced associative pairings are necessary for $24 \mathrm{~h}$ maintenance. Such rates of appetitive learning might indicate that, in ecological terms, a single feeding bout and its consequential associative pairing will only become relevant and informative in the long-term if consolidated by further identical, but short-spaced, feeding events.

In crickets, omnivores which feed persistently on similar food items after sampling the various organic materials available (Matsumoto and Mizunami, 2002a), the olfactory appetitive association was maintained only for $24 \mathrm{~h}$ when they were at least submitted to a two-trial training (Unoki et al., 2006). It has been suggested that omnivorous hemimetabolous insects have a particularly long olfactory memory retention; this has been shown to last for more than 4 weeks in the cockroach (Sakura and Mizunami, 2001) and up to 10 weeks in crickets (Matsumoto and Mizunami, 2002b). These long-lasting, potentially lifetime olfactory memories were observed in individuals trained during three or more consecutive days under a differential conditioning schedule (Sakura and Mizunami, 2001; Matsumoto and Mizunami, 2002b), where reconsolidation processes could be responsible for the long-lasting salience. However, honeybee foragers, which are highly motivated to search for nectar and pollen in floral patches and quickly learn their locations (Winston, 1987), can form olfactory memories that last up to 3 days with only three training trials (Hammer and Menzel, 1995). In our study, longer retention times were not investigated, but the relatively high conditioned preference shown by block- trained locusts after $24 \mathrm{~h}$ suggests that olfactory memories may be retained for longer periods.

Locusts can learn the nutritional content and magnitude of a food reward, and they can use these memories to make relevant behavioural decisions (Simpson and White, 1990; Behmer et al., 2005; Pompilio et al., 2006). Simpson and White demonstrated that L. migratoria trained over 2 days associate an odour with the protein content of that diet (Simpson and White, 1990). These protein-odour associations modify behaviour after $4 \mathrm{~h}$ of protein deprivation. A direct comparison with our present results is difficult because previously, the number of exposures to paired odour and protein was not controlled, but our results show that even a single training trial is sufficient to induce a short-term change in odour preference. Controlling the timing, duration, strength and number of associations experienced by individuals will provide a more detailed understanding of how learning in locusts influences their feeding strategy.
CS

ITI

PER

POR

US

\section{LIST OF ABBREVIATIONS}

\author{
conditioned stimulus
}

inter-trial interval

proboscis extension reflex

palp opening response

unconditioned stimulus

\section{ACKNOWLEDGEMENTS}

We would like to thank Glenn Harrison for designing and building the odourrelease timer and Steve Rogers for comments on the manuscript. P.M.V.S. is supported by the International Neuroscience Doctoral Programme, Portugal

(Fundação Calouste Gulbenkian, Fundação Champalimaud and Fundação para a Ciência e Tecnologia; SFRH/BD/33278/2007). S.R.O. is the recipient of a University Research Fellowship from the Royal Society, London, UK, and Research Grant BB/H002537/1 from the BBSRC. J.E.N. is the recipient of a University Research Fellowship from the Royal Society, London, UK.

\section{REFERENCES}

Balderrama, N. (1980). One trial learning in the American cockroach, Periplaneta americana. J. Insect Physiol. 26, 499-504.

Behmer, S. T. (2009). Insect herbivore nutrient regulation. Annu. Rev. Entomol. 54 165-187.

Behmer, S. T., Elias, D. O. and Bernays, E. A. (1999). Post-ingestive feedbacks and associative learning regulate the intake of unsuitable sterols in a generalist grasshopper. J. Exp. Biol. 202, 739-748.

Behmer, S. T., Belt, C. E. and Shapiro, M. S. (2005). Variable rewards and discrimination ability in an insect herbivore: what and how does a hungry locust learn? J. Exp. Biol. 208, 3463-3473.

Bernays, E. A. (1993). Aversion learning and feeding. In Insect Learning: Ecological and Evolutionary Perspectives (ed. D. R. Papaj and A. C. Lewis), pp. 1-17. New York: Chapman and Hall.

Bernays, E. A. and Lee, J. (1988). Food aversion learning in the polyphagous grasshopper Schistocerca americana. Physiol. Entomol. 13, 131-137.

Bitterman, M., Menzel, R., Fietz, A. and Schäfer, S. (1983). Classical conditioning of proboscis extension in honeybees (Apis mellifera). J. Comp. Physiol. 97, 107-119.

Blaney, W. and Chapman, R. (1970). The functions of the maxillary palps of Acrididae (Orthoptera). Entomol. Exp. Appl. 13, 363-376.

Boisvert, M. J. and Sherry, D. F. (2006). Interval timing by an invertebrate, the bumble bee Bombus impatiens. Curr. Biol. 16, 1636-1640.

Carew, T. and Sahley, C. (1986). Invertebrate learning and memory: from behavior to molecules. Annu. Rev. Neurosci. 9, 435-487.

Chabaud, M. A., Devaud, J. M., Pham-Delègue, M. H., Preat, T. and Kaiser, L. (2006). Olfactory conditioning of proboscis activity in Drosophila melanogaster. J. Comp. Physiol. A 192, 1335-1348.

Chaffiol, A., Laloi, D. and Pham-Delègue, M. H. (2005). Prior classical olfactory conditioning improves odour-cued flight orientation of honeybees in a wind tunnel. $J$ Exp. Biol. 208, 3731-3737.

Chapman, R. and Sword, G. (1993). The importance of palpation in food selection by a polyphagous grasshopper (Orthoptera: Acrididae). J. Insect Behav. 6, 79-91.

Chittka, L. and Niven, J. (2009). Are bigger brains better? Curr. Biol. 19, 995-1008.

Daly, K. C. and Smith, B. H. (2000). Associative olfactory learning in the moth Manduca sexta. J. Exp. Biol. 203, 2025-2038.

De Boer, J. G. and Dicke, M. (2006). Olfactory learning by predatory arthropods. Anim. Biol. 56, 143-155.

Dukas, R. (2008). Evolutionary biology of insect learning. Annu. Rev. Entomol. 53, 145-160.

Dukas, R. and Bernays, E. A. (2000). Learning improves growth rate in grasshoppers. Proc. Natl. Acad. Sci. USA 97, 2637-2640. 
Dukas, R. and Simpson, S. J. (2009). Locusts show rapid individual learning but no social learning about food. Anim. Behav. 78, 307-311.

Fan, R., Anderson, P. and Hansson, B. (1997). Behavioural analysis of olfactory conditioning in the moth Spodoptera littoralis (Boisd.) (Lepidoptera: Noctuidae). J. Exp. Biol. 200, 2969-2976.

Giurfa, M., Zhang, S., Jenett, A., Menzel, R. and Srinivasan, M. V. (2001). The concepts of 'sameness' and 'difference' in an insect. Nature 410, 930-933.

Guerrieri, F. J. and d'Ettorre, P. (2010). Associative learning in ants: conditioning of the maxilla-labium extension response in Camponotus aethiops. J. Insect Physiol. $56,88-92$.

Hammer, M. and Menzel, R. (1995). Learning and memory in the honeybee. J. Neurosci. 15, 1617-1630.

Hartlieb, E. (1996). Olfactory conditioning in the moth Heliothis virescens. Naturwissenschaften 83, 87-88

Laloi, D., Sandoz, J. C., Picard-Nizou, A. L., Marchesi, A., Pouvreau, A., Taséi, J. N., Poppy, G. and Pham-Delègue, M. H. (1999). Olfactory conditioning of the proboscis extension in bumble bees. Entomol. Exp. Appl. 90, 123-129.

Laurent, G. (2002). Olfactory network dynamics and the coding of multidimensional signals. Nat. Rev. Neurosci. 3, 884-895.

Lee, J. and Bernays, E. A. (1990). Food tastes and toxic effects: associative learning by the polyphagous grasshopper Schistocerca americana (Drury) (Orthoptera: Acrididae). Anim. Behav. 39, 163-173.

Margulies, C., Tully, T. and Dubnau, J. (2005). Deconstructing memory in Drosophila. Curr. Biol. 15, 700-713.

Matsumoto, Y. and Mizunami, M. (2000). Olfactory learning in the cricket Gryllus bimaculatus. J. Exp. Biol. 203, 2581-2588.

Matsumoto, Y. and Mizunami, M. (2002a). Temporal determinants of long-term retention of olfactory memory in the cricket Gryllus bimaculatus. J. Exp. Biol. 205, 1429-1437.

Matsumoto, Y. and Mizunami, M. (2002b). Lifetime olfactory memory in the cricket Gryllus bimaculatus. J. Comp. Physiol. 188, 295-299.

Menzel, R. (1999). Memory dynamics in the honeybee. J. Comp. Physiol. 185, 323340.

Menzel, R., Gaio, U., Gerberding, M., Nerarava, E. and Wittstock, S. (1993). Formation of long-term olfactory memory in honeybees does not require protein synthesis. Naturwissenschaften $\mathbf{8 0}, 380-382$.

Mery, F. and Kawecki, T. J. (2005). A cost of long-term memory in Drosophila. Science 308, 1148
Papaj, D. R. and Prokopy, R. J. (1989). Ecological and evolutionary aspects of learning in phytophagous insects. Annu. Rev. Entomol. 34, 315-350.

Pompilio, L., Kacelnik, A. and Behmer, S. (2006). State-dependent learned valuation drives choice in an invertebrate. Science 311, 1613-1614.

Rankin, C. and Dubnau, J. (2007). Memories of worms and flies: from gene to behavior. In Invertebrate Neurobiology (ed. R. Greenspan and G. North), pp. 309 346. New York: Cold Spring Harbor Laboratory Press.

Raubenheimer, D. and Blackshaw, J. (1994). Locusts learn to associate visual stimuli with drinking. J. Insect Behav. 7, 569-575.

Raubenheimer, D. and Tucker, D. (1997). Associative learning by locusts: pairing of visual cues with consumption of protein and carbohydrate. Anim. Behav. 54, 14491459.

Rehder, V. (1987). Quantification of the honeybee's proboscis reflex by electromyographic recordings. J. Insect Physiol. 33, 501-507.

Sakura, M. and Mizunami, M. (2001). Olfactory learning and memory in the cockroach Periplaneta americana. Zool. Sci. 18, 21-28.

Sandoz, J. C., Laloi, D., Odoux, J. F. and Pham-Delègue, M. H. (2000). Olfactory information transfer in the honey bees: compared efficiency of classical conditioning and early exposure. Anim. Behav. 59, 1025-1034.

Simpson, S. J. and Raubenheimer, D. (2000). The hungry locust. Adv. Study Behav. 29, $1-43$.

Simpson, S. J. and White, P. (1990). Associative learning and locust feeding: evidence for a 'learned hunger' for protein. Anim. Behav. 40, 506-513.

Simpson, S. J., Simmonds, M. S. and Blaney, W. M. (1988). A comparison of dietary selection behaviour in larval Locusta migratoria and Spodoptera littoralis. Physiol. Entomol. 13, 225-238.

Sokal, R. and Rohlf, F. (1998). Biometry: the Principles and Practice of Statistics in Biological Research. New York: W. H. Freeman and Company.

Szentesi, A. and Bernays, E. A. (1984). A study of behavioural habituation to a feeding deterrent in nymphs of Schistocerca gregaria. Physiol. Entomol. 9, 329-340.

Tully, T. and Quinn, W. G. (1985). Classical conditioning and retention in normal and mutant Drosophila melanogaster. J. Comp. Physiol. A 157, 263-277.

Unoki, S., Matsumoto, Y. and Mizunami, M. (2006). Roles of octopaminergic and dopaminergic neurons in mediating reward and punishment signals in insect visual learning. Eur. J. Neurosci. 24, 2031-2038.

Winston, M. L. (1987). The Biology of the Honey Bee. Cambridge, MA: Harvard University Press.

Zar, J. (1999). Biostatistical Analysis. Englewood Cliffs, NJ: Prentice Hall. 